\title{
The diagnosis of ectopic pregnancy in an accident and emergency department
}

\author{
M. J. CLANCY \& R. N. ILLINGWORTH \\ Accident and Emergency Department, St fames's University Hospital, Leeds, England
}

\section{SUMMARY}

The correct diagnosis was initially suspected in $32(53 \%)$ of 60 patients with ectopic pregnancy who attended an accident and emergency department. Incorrect diagnoses were made because ectopic pregnancy was not considered or because relevant symptoms and signs were missed or misinterpreted. Three patients had been 'sterilized'. Twenty-four patients $(40 \%)$ had abdominal pain or vaginal bleeding for more than 1 week before attending. Fever and leucocytosis were wrongly attributed to pelvic infection. Pregnancy tests were positive in $56 \%$ of the patients tested.

\section{INTRODUCTION}

Ectopic pregnancy occurs in 0.5 to $2 \%$ of pregnancies and appears to be increasing in frequency (Baskett, 1985; Makinen, 1987). It is the cause of $11 \%$ of deaths associated with pregnancy (Turnbull et al., 1986) but is often misdiagnosed initially (Brenner $e t$ al., 1980). We wished to determine the accuracy of diagnosis of ectopic pregnancy in an accident and emergency (A\&E) department and consider how this could be improved.

\section{METHODS}

Patients discharged from St James's University Hospital, Leeds, in 1983 to 1986 with a diagnosis of ectopic pregnancy were identified from the hospital computer records. The notes of those patients who had initially attended the A\&E department were analysed for factors associated with ectopic pregnancy, the presenting symptoms and signs, the initial diagnosis and investigations and the subsequent outcome.

Correspondence: Dr R. N. Illingworth, Consultant in Accident and Emergency Medicine, Accident and Emergency Department, St fames's University Hospital, Beckett Street, Leeds LS9 7TF, England 


\section{RESULTS}

The notes of 60 patients were available and two others could not be traced. The 60 women were aged 17 to 45 years (mean 28 years).

Twenty-six patients $(43 \%)$ were referred to the A\&E department by a general practitioner. Two patients had recently been seen in other A\&E departments and eight in gynaecology departments. Three of the latter had had recent uterine curettage for presumed incomplete abortions and had been discharged but their symptoms had not resolved.

\section{Previous history}

Twenty-nine patients (48\%) had pre-existing conditions associated with an increased risk of ectopic pregnancy (Table 1). Ten patients had been investigated for infertility and three had had tubal ligations or diathermy for sterilization.

\section{Symptoms and signs}

The patients' symptoms and signs are listed in Table 2. Abdominal pain was common ( 57 patients, $95 \%$ ) and in 24 cases the pain had been present for more than a week. One patient had pain for 4 weeks before presentation and was later found to have a incarcerated tubal ectopic. Recent amenorrhoea was common (41 patients, $68 \%$ ) bu many patients had then had irregular vaginal bleeding and mistaken it for a normal period. In 21 patients (35\%) the vaginal bleeding had lasted for more than 1 week. In eight patients symptoms of pregnancy such as breast tenderness were not recorded by A\&E doctors but were noted later by a gynaecologist. Similarly in three patients with fainting or dizziness these symptoms were not recorded in the A\&E department.

Abdominal tenderness occurred in 42 patients $(70 \%)$. Vaginal examinations were

Table 1 Associated factors in 60 patients with ectopic pregnancy

\begin{tabular}{|c|c|}
\hline & Incidence \\
\hline Investigations for infertility (Wyper, 1962) & $10(17 \%)$ \\
\hline Previous abdominal surgery (Tindall, 1987) & $9(15 \%)$ \\
\hline Intra-uterine contraceptive device used within previous year (Ory, 1981) & $8(13 \%)$ \\
\hline Previous ectopic pregnancy (Scott, 1981) & $4(7 \%)$ \\
\hline Previous pelvic infection (Brenner et al., 1980) & $4(7 \%)$ \\
\hline Progestogen only contraceptive pill (Liukko et al., 1977) & $4(7 \%)$ \\
\hline Tubal ligation or diathermy (Wolf \& Thompson, 1980) & $3(5 \%)$ \\
\hline Patients with none of these factors & $31(52 \%)$ \\
\hline
\end{tabular}


Table 2 Symptoms and signs in 60 patients with ectopic pregnancy

\begin{tabular}{lr}
\hline & Incidence \\
\hline Abdominal pain & $57(95 \%)$ \\
Amenorrhoea & $41(68 \%)$ \\
Vaginal bleeding & $45(75 \%)$ \\
Nausea and vomiting & $29(48 \%)$ \\
Breast tenderness & $19(32 \%)$ \\
Faintness, dizziness or weakness & $18(30 \%)$ \\
Chest or shoulder pain & $9(15 \%)$ \\
Pain on defaecation & $4(7 \%)$ \\
Abdominal tenderness & $42(70 \%)$ \\
Adnexal tenderness & $32(53 \%)$ \\
Cervical excitation & $25(42 \%)$ \\
Adnexal mass & $11(18 \%)$ \\
Uterine enlargement & $22(37 \%)$ \\
Hypovolaemic shock & $7(12 \%)$ \\
Pyrexia (37.5 ${ }^{\circ} \mathrm{C}$ or higher) & $6(10 \%)$ \\
\hline
\end{tabular}

performed by $A \& E$ doctors in 31 patients: in nine of these patients the examination was thought to be normal but adnexal tenderness, adnexal mass or cervical excitation were noted later by a gynaecologist. Seven patients $(12 \%)$ presented in hypovolaemic shock. Six patients had an oral temperature of $37.5^{\circ} \mathrm{C}$ or higher.

\section{Investigations}

The results of pregnancy tests were recorded in 45 cases, 25 (56\%) being positive. During the years studied different pregnancy tests were used in the pathology laboratory, with higher sensitivity tests being used intermittently from 1985 . The white blood cell count was recorded in 43 patients and was raised (over $11 \times 10^{9} / 1$ ) in 14 cases, the highest recorded being $23 \times 10^{9} / 1$.

Abdominal ultrasound scans were performed in 22 patients and in 16 showed evidence suggesting or consistent with ectopic pregnancy, that is an adnexal mass or an empty uterus. In two cases the examination was thought to be normal and in four a diagnosis other than ectopic pregnancy was suggested: in three cases an incomplete or missed abortion and in one patient a hydrosalpinx. In one case a left sided tubal pregnancy was noticed during an ultrasound scan for gallstones in a woman with characteristic symptoms of biliary colic: no gallstones were found and her symptoms settled after salpingectomy. One patient had an intravenous pyelogram and another had plain abdominal erect and supine radiographs, which were normal. 


\section{Diagnosis and management}

Ectopic pregnancy was mentioned in the referral letter as a possible diagnosis in $14 \stackrel{\mathrm{D}}{\mathrm{Q}}$ $(54 \%)$ of the 26 patients sent to the A\&E department by general practitioners. Ectopic pregnancy was recorded as the primary diagnosis in the A\&E department in 28 of the 60 cases $(47 \%)$ and as a differential diagnosis in another four $(7 \%)$. Another 19 patients $(32 \%)$ were referred by $A \& E$ doctors to gynaecologists although ectopic pregnancy was not mentioned in the notes. The gynaecologists initially considered ectopic pregnancy as the principal diagnosis in $30(59 \%)$ and as a differential diagnosis in another $18(35 \%)$ of the 51 patients referred to them by A\&E doctors. The most common misdiagnoses were pelvic inflammatory disease, threatened abortion and ovarian cysts.

Seven patients were admitted to the care of general or urological surgeons after being seen by their senior house officers or registrars, the provisional diagnoses being appendicitis, non-specific abdominal pain, ruptured spleen, perforated peptic ulcer, renal colic or pyelonephritis.

Four patients were initially sent home from the A\&E department with diagnoses of pelvic inflammatory disease (two cases, both seen by gynaecologists), biliary colic (seen by a surgical registrar) and urinary infection. These patients were admitted at a second visit. The patient with a urinary infection developed signs of pyelonephritis and was admitted for urological care, the diagnosis of ectopic pregnancy being made one week later.

All patients had a laparotomy, usually with salpingectomy, and survived to leave hospital.

\section{DISCUSSION}

The diagnosis of ectopic pregnancy is sometimes simple but may be notoriously difficult. In previous studies the correct diagnosis was made initially in only about $50 \%$ of patients (Brenner et al., 1980; Weckstein, 1987). The results are similar in this study. It is clear that in some cases the diagnosis was missed because the possibility of pregnancy had not been considered, for example in patients who had been 'sterilized'. Occasionally patients deny the possibility of pregnancy even when specific enquiry is made. Ectopic pregnancy may even occur after hysterectomy (Buchan, 1980). Knowledge of factors associated with ectopic pregnancy (Table 1) may make one suspect the diagnosis more often in appropriate cases. It was notable that $10(17 \%)$ of the patients in this series had previously been investigated for infertility.

In some patients relevant items in the history or examination were initially overlooked. Vaginal examination may give useful diagnostic information to a skilled examiner but might precipitate rupture of an ectopic pregnancy. We would advise that if ectopic pregnancy is seriously considered then vaginal examination should only be performed by an experienced gynaecologist.

It was clear from the notes that in some cases the doctor obtained adequate information but then interpreted it wrongly. A history of pain or vaginal bleeding lasting over a week was sometimes thought, incorrectly, to be incompatible with an ectopic pregnancy. Pyrexia and a raised white cell count were often regarded as 
evidence of infection, suggesting salpingitis as the problem rather than ectopic pregnancy. In a few patients the presenting features were typical of another condition, for example pyelonephritis, and even in retrospect it is difficult to see how the correct diagnosis could have been made initially.

Urinary pregnancy tests are helpful in confirming pregnancy but may be negative in patients with ectopic pregnancies. The newer highly sensitive pregnancy tests which detect human chorionic gonadotrophin at concentrations of $50 \mathrm{IU} / 1$ are positive in more than $90 \%$ of ectopic pregnancies (Barnes et al., 1985) whereas the older nonspecific tests are positive in only 50 to $70 \%$ of cases (Baskett, 1985). Ultrasound scans may appear normal, as in some of our patients and previous reports (Kelly et al., 1979), but are often helpful in confirming an intrauterine pregnancy or demonstrating an adnexal mass (Newton, 1988). Culdocentesis, the aspiration of non-clotting blood from the pouch of Douglas, has been recommended as a diagnostic procedure (Brenner et al., 1980) but was not performed in any of our patients: culdocentesis does not seem an appropriate investigation if highly sensitive pregnancy tests and ultrasound facilities are available. Laparoscopy may be needed to confirm the diagnosis of ectopic pregnancy but this is not a procedure performed in $A \& E$ departments.

Computer-aided diagnosis of acute abdominal pain has proved useful (Adams et al., 1986) and was available in the $A \& E$ department during the years studied. The main diagnostic program concerns only pain lasting less than one week and does not include ectopic pregnancy in the diagnostic prediction. A supplementary program covering ectopic pregnancy and other gynaecological problems was also available but the notes contain no record of its use in the patients studied. Suitable computer programs could be helpful in assisting inexperienced doctors with the interpretation of patients' symptoms, signs and investigations and suggesting relevant diagnoses, such as ectopic pregnancy, which may not have been considered.

The proper treatment of patients with ectopic pregnancy in an A\&E department requires suspicion of the condition, careful assessment and interpretation of symptoms and signs, appropriate investigations and prompt referral for gynaecological care. Early diagnosis should reduce the morbidity and mortality associated with ectopic pregnancy.

\section{ACKNOWLEDGEMENTS}

We are grateful to our colleagues in obstetrics and gynaecology for allowing us access to their patients' records and to the medical records staff for their assistance.

\section{REFERENCES}

Adams I. D., Chan M., Clifford P. et al., (1986) Computer-aided diagnosis of abdominal pain: a multicentre study. British Medical fournal 293, 800-4.

Barnes R. B., Roy S., Yee B., Duda M. J. \& Mishell D. R. (1985) Reliability of urinary pregnancy tests in the diagnosis of ectopic pregnancy. The fournal of Reproductive Medicine 30, 827-31.

Baskett T. F. (1985) Essential Management of Obstetric Emergencies. John Wiley, Chichester. 
Brenner P. F., Roy S. \& Mishell D. R. (1980). Ectopic pregnancy: a study of 300 consecutive surgically treated cases. Fournal of the American Medical Association 243, 673-6.

Buchan P. C. (1980) Ectopic pregnancy following total hysterectomy. British fournal of Clinical Practice 34, $\stackrel{\rrbracket}{\circ}$ 227-8.

Kelly M. 'T., Santos-Ramos R. \& Duenhoelter J. H. (1979). The value of sonography in suspected ectopic $\stackrel{\overrightarrow{\vec{S}}}{\overrightarrow{7}}$ pregnancy. Obstetrics and Gynecology 53, 703-8.

Liukko P., Erkkola R. \& Laakso L. (1977) Ectopic pregnancies during use of low-dose progestogens for oral contraception. Contraception 16, 575-80.

Makinen J. I. (1987) Ectopic pregnancy in Finland 1967-83: a massive increase. British Medical fournal 294, 740-1.

Newton J. (1988) Ectopic pregnancy. British Medical fournal 297, 633-5.

Ory H. W. et al., (1981) Ectopic pregnancy and intrauterine contraceptive devices: new perspectives. Obstetrics and Gynecology 57, 137-43.

Scott J. S. (1981) Ectopic pregnancy. In: Integrated Obstetrics and Gynaecology for Postgraduates, 3rd Edition. Dewhurst J. (Ed) Blackwell Scientific Publications, Oxford.

Tindall V. R. (1987). Feffcoate's Principles of Gynaecology, 5th Edition. Butterworths, London.

Turnbull A. C., Tindall V. R., Robson G., Dawson I. M. P., Cloake E. P. \& Ashley J. S. A. (1986) Report on Confidential Enquiries into Maternal Deaths in England and Wales 1979-1981. Her Majesty's Stationery Office, London.

Weckstein L. N. (1987) Clinical diagnosis of ectopic pregnancy. Clinics in Obstetrics and Gynecology 30, 236- 윽 45.

Wolf G. C. \& Thompson N. J. (1980) Female sterilization and subsequent ectopic pregnancy. Obstetrics and $\mathcal{C}$ Gynecology 55, 17-9.

Wyper J. F. B. (1962) Pregnancy after primary infertility investigations. British Medical fournal 1, $273-6$. 